\title{
Financial Integration, Macroeconomic Volatility and Welfare
}

September 21, 2006

Martin D. D. Evans ${ }^{1}$

Georgetown University and NBER

Department of Economics

Washington DC 20057

Tel: (202) 338-2991

evansm1@georgetown.edu
Viktoria Hnatkovska

UBC

Department of Economics

Vancouver BC V6K 3W9

Tel: (604) 822-5941

hnatkovs@interchange.ubc.ca

\begin{abstract}
This paper studies the effects of financial integration on macroeconomic volatility and welfare. We examine a two-sector (tradable and nontradable), twocountry world economy with production in which both stocks and bonds are traded internationally, but markets are incomplete. The effects of integration are examined by comparing the equilibrium properties of the model under three financial configurations: autarky, low integration and high integration. The model predicts a non-monotonic relationship between the degree of financial integration and the volatility of several macroeconomic variables. Greater integration is initially associated with more volatile consumption and output, but as integration proceeds further volatility declines. We also find that while increased integration allows for significantly greater risk-sharing between countries, the improvement in welfare can be very small.
\end{abstract}

JEL Classification: D52; F36; G11.

Keywords: Globalization; Incomplete Markets; Volatility; Welfare.

\footnotetext{
${ }^{1}$ We thank Mick Devereux, Philip Lane, and participants of the "Macroeconomics of Financial Globalization" session at the EEA-ESEM 2006 meetings for the comments.
} 


\section{Introduction}

International financial markets have undergone dramatic changes in the past twenty years. Gross capital flows in industrial countries have increased by 300 percent in just the last decade, while the financial markets of developing countries have experienced even deeper transformations. The aim of this paper is to provide a theoretical assessment of the consequences of increased integration in world financial markets. In particular, our analysis focuses on how greater access to foreign capital markets affects the volatility of key macroeconomic variables, like consumption and output, and the welfare of households.

Greater access to foreign financial markets can affect macroeconomic volatility through two main channels. First, access to a wider array of financial assets allows for greater risk-sharing by households with the result that consumption becomes less susceptible to country-specific shocks. Second, greater access to world capital markets can induce greater within-country specialization in production leading to the amplification of sectoral shocks and their transmission between countries. The effects of greater integration on macroeconomic volatility depend on which channel dominates. Our model allows us to identify and quantify the importance of these channels at different stages of integration. While macroeconomic volatility is relatively easy to measure empirically, it is the welfare implications of integration that are our ultimate concern, and so also figure in our analysis.

This paper equates greater financial integration with the gradual removal of the restrictions on access to foreign financial markets. Specifically, we compare three equilibria in the two-country general equilibrium model developed in Evans and Hnatkovska (2005). In the financial autarky (FA) equilibrium, households can only hold their savings in the equities issued by domestic firms. Under low integration (LI), we expand the array of available assets to include a single noncontingent bond that is traded internationally. In the high financial integration (HI) equilibrium the array of asset is further expanded to include the equities issued by a subset of foreign firms. One important aspect of our analysis is that we do not equate HI with complete risk-sharing. The degree of risk-sharing does indeed rise as we move from FA to LI and then to the HI equilibria, but the available menu of assets is never sufficient to permit complete risk-sharing.

Our model produces a hump-shaped relation between the degree of financial integration and macroeconomic volatilities. Aggregate consumption and production volatilities increase as we move from FA to LI, even in the frictionless environment of our model. The risk-sharing benefits of financial integration only appear in the form of lower volatilities as we move from the LI to HI equilibria.

The intuition behind this result is straightforward. In our model households aim 
to smooth aggregate consumption and maintain a balanced basket of traded and nontraded goods. Their ability to achieve both these objectives depends on the available array of assets, and therefore changes with the degree of integration. As integration proceeds, the widening array of available assets allows households to smooth their consumption of tradables so their volatility declines as we move from FA to LI and then on to HI. At the same time, the desire to balance the consumption of tradable and nontradable goods coupled with the availability of more financial assets increases the correlation between the consumption of the two goods. In the move from the FA to LI equilibria, the increase in correlation dominates the fall the volatility of tradable consumption so that the volatility of aggregate consumption rises. Then, as integration proceeds further (i.e. from LI to $\mathrm{HI}$ ), the correlation effect is dominated by the fall in the volatility of tradable consumption leading to a decline in aggregate consumption volatility.

The non-monotonic relationship between integration and consumption volatility does not carry over to welfare. Although the degree of risk sharing rises quite dramatically as we move from the FA to the HI equilibria, the improvement in unconditional welfare is extremely small. Nevertheless, the susceptibility of household welfare to specific shocks does vary with the degree of integration. In particular, the susceptibility of household welfare to foreign productivity shocks is higher under LI that either FA or HI. This finding suggest that opening financial markets can be costly if the world economy is hit by a particular sequence of shocks during the transition process.

Our findings complement and extend several results in the literature. Our humped-shaped pattern in consumption and output volatility is consistent with the empirical findings of Kose et. al. (2003) in their study of 76 countries between 1960 and 1999. In contrast, earlier theoretical models by Baxter and Crucini (1994), Sutherland (1998), Heathcote and Perri (2002) show that the volatility of consumption falls as risk-sharing increases. Our approach differs from existing models in two important respects: First, we do not assume that greater financial integration facilitates complete risk-sharing. Second, our model does not include any frictions, such as transactions costs. ${ }^{2}$ Studying a model with many assets, incomplete risk-sharing and frictions is a very complex task that we leave for the future.

The remainder of the paper in organized as follows. The model is outlined in Section 2 . Section 3 presents the results on macroeconomic volatility and welfare. Section 4 concludes.

\footnotetext{
${ }^{2}$ Recent models of financial integration with frictions include Buch and Pierdzioch (2003) and Leblebicioglu (2005).
} 


\section{The Model}

We study the impact of financial integration in the model developed in Evans and Hnatkovska (2005). In this model the world economy consists of two identical countries, called HOME $(\mathrm{H})$ and FOREIGN $(\mathrm{F})$. Each country is populated by a continuum of identical households and firms in the traded and nontraded goods sectors. Households consume and invest in different assets. Firms in both sectors are perfectly competitive, and issue equity that is traded on the domestic stock market. Below we briefly outline the production and household sectors of the model. We refer interested readers to Evans and Hnatkovska (2005) for further model details.

\subsection{Production}

The traded goods sector in each country is populated by a continuum of identical firms. Each firm owns its capital and issues equity on the domestic stock market. Period $-t$ production by a representative firm in the traded goods sector of the $\mathrm{H}$ country is $Y_{t}^{\mathrm{T}}=Z_{t}^{\mathrm{T}} K_{t}^{\theta}$ with $\theta>0$, where $K_{t}$ denotes the stock of physical capital at the start of the period, and $Z_{t}^{\mathrm{T}}$ is the exogenous state of productivity. The output of traded goods in the $\mathrm{F}$ country, $\hat{Y}_{t}^{\mathrm{T}}$, is analogously defined. Hereafter we use " " to denote foreign variables. The traded goods produced by $\mathrm{H}$ and $\mathrm{F}$ firms are identical and can be costlessly transported between countries.

Let $P_{t}^{\mathrm{T}}$ denote the ex-dividend price of a share in the representative $\mathrm{H}$ firm producing traded goods at the start of period $t$, and let $D_{t}^{\mathrm{T}}$ be the dividend per share paid at period $t . P_{t}^{\mathrm{T}}$ and $D_{t}^{\mathrm{T}}$ are measured in terms of $\mathrm{H}$ traded goods. We normalize the number of shares issued by the representative traded-good firm to unity so the value of the firm at the start of period $t$ is $P_{t}^{\mathrm{T}}+D_{t}^{\mathrm{T}}$. H firms allocate output to investment, $I_{t}$, by solving

$$
\max _{I_{t}}\left(D_{t}^{\mathrm{T}}+P_{t}^{\mathrm{T}}\right)
$$

subject to $K_{t+1}=(1-\delta) K_{t}+I_{t}$ and $D_{t}^{\mathrm{T}}=Z_{t}^{\mathrm{T}} K_{t}^{\theta}-I_{t}$ where $\delta>0$ is the depreciation rate on physical capital. The representative firm in the $\mathrm{F}$ traded goods sector solves an analogous problem.

The output of nontraded goods by representative firms in the $\mathrm{H}$ country is given by $Y_{t}^{\mathrm{N}}=\kappa Z_{t}^{\mathrm{N}}$, where $\kappa>0$ is a constant and $Z_{t}^{\mathrm{N}}$ denotes the period $-t$ state of nontraded good productivity. The output of nontraded goods can only be consumed by domestic households. The resulting proceeds are then distributed in the form of dividends to owners of nontraded equity.

Productivity in both sectors is governed by an exogenous productivity process. In particular, we assume that the vector $z_{t} \equiv\left[\ln Z_{t}^{\mathrm{T}}, \ln \hat{Z}_{t}^{\mathrm{T}}, \ln Z_{t}^{\mathrm{N}}, \ln \hat{Z}_{t}^{\mathrm{N}}\right]^{\prime}$ 
follows an $\mathrm{AR}(1)$ process:

$$
z_{t}=a z_{t-1}+e_{t}
$$

where $e_{t}$ is a $(4 \times 1)$ vector of i.i.d. normally distributed, mean zero shocks with covariance $\Omega_{e}$.

\subsection{Households}

Each country is populated by a continuum of households who have identical preferences over the consumption of traded and nontraded goods, $C_{t}^{\mathrm{T}}$ and $C_{t}^{\mathrm{N}}$. The preferences of a representative household in country $\mathrm{H}$ are given by

$$
\mathbb{U}_{t}=\mathbb{E}_{t} \sum_{i=0}^{\infty} \beta^{i} \ln \left(C_{t+i}\right),
$$

where $0<\beta<1$ is the discount factor, and $C_{t}=\left[\lambda_{\mathrm{T}}^{1-\phi}\left(C_{t}^{\mathrm{T}}\right)^{\phi}+\lambda_{\mathrm{N}}^{1-\phi}\left(C_{t}^{\mathrm{N}}\right)^{\phi}\right]^{1 / \phi}$, with $\phi<1$. $\lambda_{\mathrm{T}}$ and $\lambda_{\mathrm{N}}$ are the weights the household assigns to tradable and nontradable consumption, respectively. The elasticity of substitution between tradable and nontradable consumption is $(1-\phi)^{-1}>0$. Preferences for households in country $\mathrm{F}$ are similarly defined in terms of foreign consumption of tradables and nontradables, $\hat{C}_{t}^{\mathrm{T}}$ and $\hat{C}_{t}^{\mathrm{N}}$. Each period households choose their consumption of tradable and nontradable goods, and the allocation of their savings between the available array of financial assets to maximize expected lifetime utility.

\subsection{Equilibrium}

Our goal is to study how the degree of financial integration affects macroeconomic volatilities, co-movements, and welfare. For this purpose, we focus on three equilibria. First, we consider the benchmark case of financial autarky (FA). In this environment, households allocate their portfolios between equity in domestic firms producing traded and nontraded goods. Second, we consider a world with low integration (LI) where households allocate their portfolios between domestic equity and an international bond. Finally, we allow for financial integration of equity markets (HI). Here households can hold shares issued by foreign tradedgood firms as well as domestic equities, and the international bond.

An equilibrium in this economy consists of a set of goods' prices, equity prices, and a risk-free rate (for LI and HI) such that all markets clear when tradable firms optimally choose investment, and households optimally choose their consumption and portfolios taking goods' and asset prices as given. Although conceptually straightforward, finding the equilibrium of this model is a complex undertaking because in all three cases $\{$ i.e., FA, LI, HI $\}$, the array of assets avail- 
able to households is insufficient to provide complete risk-sharing. This means that the model must be solved in a decentralized manner. Specifically, we need to find the optimal behavior of firms and households given a conjecture about price dynamics and then verify that these conjectured dynamics are indeed consistent with optimal behavior and market clearing. This decentralized procedure is implemented in the new numerical solution method developed in Evans and Hnatkovska (2006) that we use here.

\subsection{Calibration}

We study the dynamics of the model for FA, LI, and HI equilibria based on a standard parametrization with one period representing one quarter. Specifically, we assume that countries are of equal size and symmetric. All households have a discount factor $\beta$ of 0.99 , consumption share parameters $\lambda_{\mathrm{T}}=\lambda_{\mathrm{N}}$ of 0.5 , and intratemporal elasticity of substitution between $\mathrm{T}$ and $\mathrm{N}$ consumption $1 /(1-\phi)$ equal to 0.74 . The capital coefficient in tradable production $\theta$ is 0.36 and the depreciation rate $\delta$ is 0.02 . The productivity shocks are trend stationary and are fully symmetric across the counties. Shocks to the tradable and nontradable sectors have autocorrelation coefficients (i.e., the diagonal elements of $a$ ) of 0.78 and 0.99 respectively (the off-diagonal elements of $a$ are zero). The productivity shocks are uncorrelated across sectors and countries and have the same variance of 0.0001 .

\section{Results}

\subsection{Volatility and Co-movements}

Table 1 compares the volatilities and co-movements of macro variables across the three equilibria. The statistics we report are computed from 50,000 years of simulated quarterly data, de-trened with the Hodrick-Prescott filter. This large sample size insures that our statistics contain very little estimation error. Three sets of results stand out: (i) the correlation pattern between the intertemporal

marginal rates of substitution for $\mathrm{H}$ and $\mathrm{F}$ households, $M R S$ and $\widehat{M R S}$; (ii) the volatility pattern in aggregate consumption, $c$; and (iii) the volatility pattern in GDP, $y$. Let us consider these in turn.

There is a marked rise in the correlation between $M R S$ and $\widehat{M R S}$ as we move from FA to LI and then to HI. Under FA the correlation is close to zero, so there is almost no risk-sharing in this equilibrium. Under LI the correlation rises to 0.5264 , so trading in international bonds facilitates a reasonable degree of risk-sharing. Risk sharing increases further under HI, but is less than complete because the correlation remains below one. 
Table 1. Volatilities and Correlations

\begin{tabular}{llccc}
\hline \hline & & $\begin{array}{c}\text { Autarky, FA } \\
(\mathrm{i})\end{array}$ & $\begin{array}{c}\text { Low Int., LI } \\
\text { (ii) }\end{array}$ & $\begin{array}{c}\text { High Int., HI } \\
\text { (iii) }\end{array}$ \\
\hline Volatilities & $c$ & 0.6676 & 0.6788 & 0.6782 \\
(\% std. dev.) & $c^{T}$ & 0.1990 & 0.1647 & 0.1560 \\
& $y$ & 0.7739 & 0.8588 & 0.8390 \\
& $c / y$ & 0.5973 & 0.7350 & 0.7578 \\
Correlations & $M R S, \widehat{M R S}$ & -0.0017 & 0.5264 & 0.6737 \\
& $c, \hat{c}$ & -0.0176 & 0.6060 & 0.7316 \\
& $c^{T}, c^{N}$ & 0.2023 & 0.4139 & 0.4357 \\
& $y, c$ & 0.7298 & 0.6331 & 0.4834 \\
\hline \hline
\end{tabular}

The second noteworthy feature concerns the volatility of aggregate consumption $c$ : It first rises and then falls as we move from FA to LI and then to HI. The intuition behind these dynamics is straightforward. Households face a trade-off between their desire to smooth aggregate consumption over time and the need to maintain balance between their consumption of tradables, $c^{\mathrm{T}}$, and nontradables, $c^{\mathrm{N}}{ }^{3}$ The structure of financial markets determines how households address this trade-off. Under LI households can use bonds to borrow and lend and thus smooth their tradable consumption. This lowers the volatility of tradable consumption relative to FA, and simultaneously increases the correlation between the two consumption goods. This can be seen in Table 1 where the volatility of tradable consumption, $c^{\mathrm{T}}$, falls from $0.1990 \%$ under FA to $0.1647 \%$ under LI. At the same time, the correlation between traded and nontraded consumption increases by more than $100 \%$. The overall effect is that the volatility of aggregate consumption is higher in LI than in FA. When shares of internationally traded equity becomes available under HI, they are used to smooth consumption and to share country-specific tradable risks. This enables households to reduce the volatility of traded consumption further to $0.1560 \%$, as well as to achieve a more balanced consumption basket (the correlation between $c^{\mathrm{T}}$ and $c^{\mathrm{N}}$ rises to $0.4357 \%$ ). Aggregate consumption, therefore, becomes less volatile than under LI.

Table 1 also shows that the volatility of GDP exhibits a nonlinear pattern. Starting at $0.7739 \%$ under FA, the standard deviation of $y$ rises to $0.8588 \%$ under

\footnotetext{
${ }^{3}$ The nature of this tradeoff depends on the curvature of the period sub-utility function and the elasticity of substitution between tradables and nontrables (see Tesar 1993, and Baxter et. al. 1998).
} 
LI, and then declines to $0.8390 \%$ under HI. The small decline in volatility between the LI and HI equilibria is not unexpected. Although risk-sharing increases significantly, the wealth effect of the transitory productivity shocks are comparatively small, so the dynamics of output are not dramatically affected by the presence of more integrated financial markets (see Baxter and Crucini 1995 and Heathcote and Perri 2002). At the same time, the volatility of the consumption-output ratio, $c / y$ increases with integration. This result is consistent with the empirical findings of Kose et.al. (2003).

\subsection{Welfare}

We now compare welfare across the three equilibria. For this purpose we use our simulations to compute the unconditional expectation of lifetime household utility (i.e. $\mathbb{U}_{t}$ in equation (3)) for the FA, LI, and HI equilibria. Then, following Kim and Kim (2003), we compute the certainty equivalent level of consumption associated with each level of welfare. These calculations show that households do gain from the opening up of access to international financial markets despite the increase in aggregate consumption volatility. However, for our preference specification, the welfare gains are very small. The welfare improvement between the HI and $\mathrm{FA}$ equilibria is equivalent to just a $0.006 \%$ permanent increase in aggregate consumption, while the gain between LI and FA equilibria is even smaller.

These welfare comparisons do not tell the whole story. Welfare varies periodby-period in response to shocks hitting the economy. Since the impact of shocks changes with the degree of financial integration, variations in household welfare could be quite different across our three equilibria. To investigate this possibility, Figure 1 shows the dynamic response of $\mathrm{H}$ and $\mathrm{F}$ lifetime utility, $\mathbb{U}_{t}$ and $\widehat{\mathbb{U}}_{t}$, to one standard deviation productivity shocks in the $\mathrm{H}$ traded and nontraded sectors under $\{\mathrm{FA}, \mathrm{LI}, \mathrm{HI}\}$ measured in \% deviations from their stochastic steady state levels.

The right hand panel of Figure 1 shows that a positive productivity shock in the $\mathrm{H}$ nontradable sector has almost identical impacts on $\mathrm{H}$ and $\mathrm{F}$ welfare in the three equilibria. In this case, access to a wider array of financial assets does not affect the welfare consequences of a shock. By contrast, the left hand panel shows that the effects of traded productivity shocks differ. Under FA, households in the $\mathrm{H}$ country are the sole beneficiary of a positive shock in the $\mathrm{H}$ traded sector. The welfare of $\mathrm{H}$ households initially increases by $0.016 \%$, and then slowly reverts back to its stochastic steady state level. By contrast, the welfare of $\mathrm{F}$ households remains unchanged. Under LI, the same shock has an identical initial impact on $\mathrm{H}$ welfare, but its effects continue indefinitely. This permanent welfare gain is matched by the welfare loss to F households. Productivity shocks in the traded sector have permanent impacts on the conditional welfare across the 
world economy under LI because they lead to a redistribution of wealth. Finally, under HI, all households insure themselves against country-specific traded shocks by diversifying their holdings of traded equity. As a consequence, all households temporarily benefit from the effects of a positive traded productivity shock in the H country.
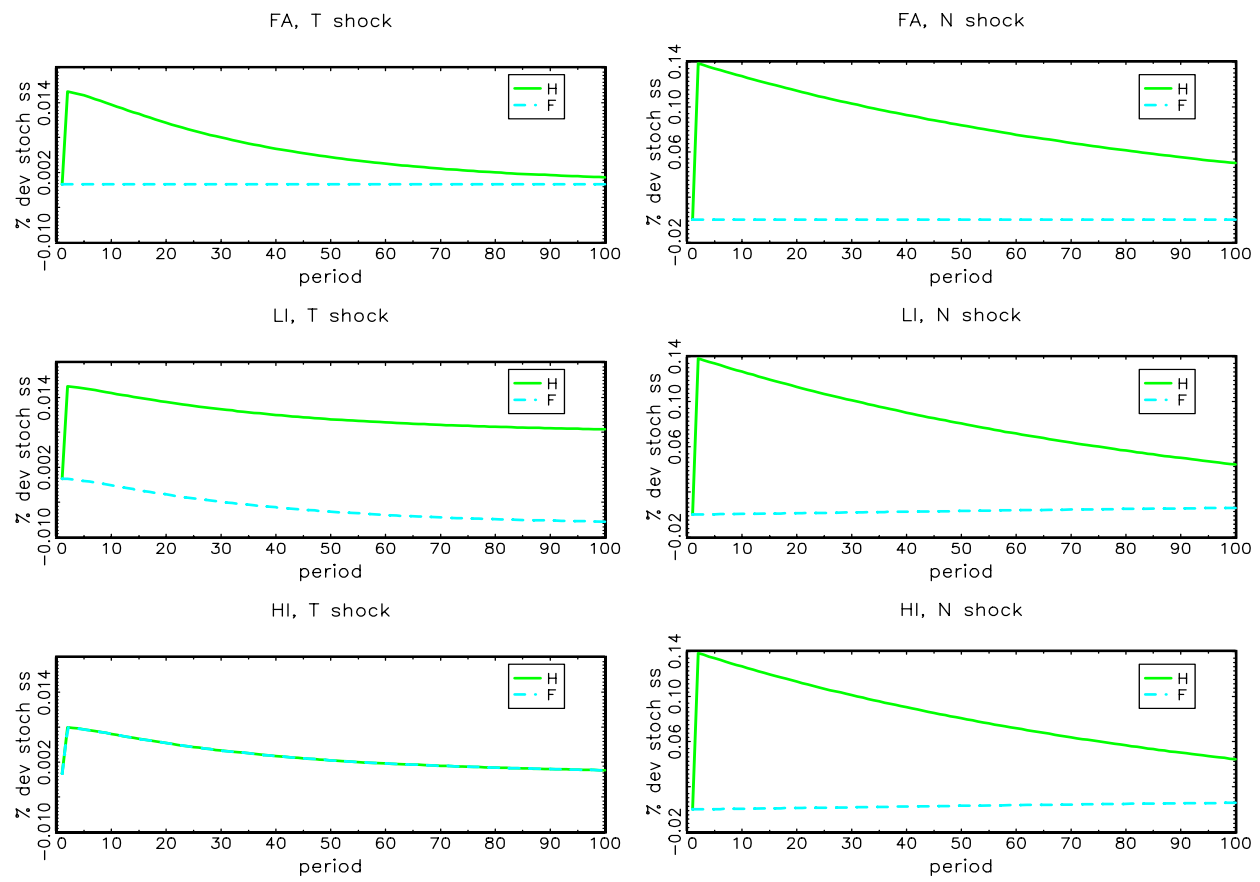

Figure 1. Conditional welfare impulse responses.

Figure 1 illustrates one potential pitfall of greater financial integration. Although the move from FA to LI and HI makes households unconditionally better off (by a small amount), the transition could be costly if the world economy is hit by a particular sequence of productivity shocks. In particular, Figure 1 shows that $\mathrm{F}$ households are susceptible to permanent welfare losses under LI if there is a positive productivity shock in the $\mathrm{H}$ traded goods sector. These welfare losses could have been avoided under FA and they will turn into gains under HI, but they represent a risk to $\mathrm{F}$ households until they have greater access to world financial markets.

\section{Conclusion}

This study analyzes the link between financial integration and macroeconomic volatilities, and the channels through which the two interact. After accounting 
for varying degree of financial integration in a frictionless model with incomplete asset markets, we find that financial integration initially intensifies consumption and production volatilities, but lowers them as countries open their financial markets further. We also find that while greater integration can facilitate much greater risk-sharing, it need not lead to a dramatic improvement in unconditional welfare. At the same time, the re-distributive effects of integration in terms of conditional welfare can be large.

\section{References}

[1] Baxter, M. and M. J. Crucini (1995). "Business Cycles and the Asset Structure of Foreign Trade", International Economic Review 36, pp. 821-854.

[2] Baxter, M., U. J. Jermann, and R. G. King (1998). "Nontraded Goods, Nontraded Factors and International Non-diversification", Journal of International Economics 44, pp. 211-229.

[3] Buch, C. M. and C. Pierdzioch (2003). "The Integration of Imperfect Financial Markets: Implications for Business Cycle Volatility", Kiel Working Paper No. 1161.

[4] Evans, M. D. D. and V. Hnatkovska (2005) "International Capital Flows, Returns and World Financial Integration", NBER Working Paper No. 1170.

[5] _-___(2006). "Solving General Equilibrium Models with Incomplete Markets and Many Assets" NBER Technical Working Paper No. t0318.

[6] Heathcote, J. and F. Perri (2002). "Financial Autarky and International Business Cycles", Journal of Monetary Economics 49, pp. 601-627.

[7] Kim, J. and S. H. Kim (2003). "Spurious Welfare Reversals in International Business Cycle Models", Journal of International Economics 60, pp. 471-500.

[8] Leblebicioglu, A. (2005). "Financial Integration, Credit Market Imperfections and Consumption Smoothing", Boston College Working Paper.

[9] Kose, M. A., E. S. Prasad, and M. E. Terrones (2003). "Financial Integration and Macroeconomic Volatility", IMF Working Paper WP/03/50.

[10] Sutherland, A. (1996). "Financial Market Integration and Macroeconomic Volatility", Scandinavian Journal of Economics 98 (4), pp. 521-539.

[11] Tesar, L. L. (1993). "International Risk Sharing and Non-Traded Goods", Journal of International Economics 35, pp. 69-89. 